\title{
Separation of Free Glycerol and Glycerides from Biodiesel by Means of Liquid-Liquid Extraction
}

\author{
Ana Petracic ${ }^{1}$, Aleksandra Sander ${ }^{1, *}$, Lana Magic ${ }^{2}$ \\ ${ }^{1}$ Department of Mechanical and Thermal Process Engineering, Faculty of Chemical Engineering and Technology, University of Zagreb, \\ Zagreb, Croatia \\ ${ }^{2}$ INA-Industrija Nafte, d.d., Zagreb, Croatia
}

Email address:

apetracic@fkit.hr (A. Petracic), asander@fkit.hr (A. Sander), lana.magic@ina.hr (L. Magic)

${ }^{*}$ Corresponding author

To cite this article:

Ana Petracic, Aleksandra Sander, Lana Magic. Separation of Free Glycerol and Glycerides from Biodiesel by Means of Liquid-Liquid Extraction. Science Journal of Energy Engineering. Vol. 5, No. 4, 2017, pp. 87-94. doi: 10.11648/j.sjee.20170504.12

Received: July 2, 2017; Accepted: August 2, 2017; Published: October 31, 2017

\begin{abstract}
This paper investigates glycerol and glycerides extraction process from fresh and waste sunflower oil biodiesel. Deep eutectic solvent choline-chloride: ethylene-glycol (molar ratio 1:2.5) was used as extraction media in both batch experiments and continuous Karr column. Biodiesel was synthesized in an alkali catalysed chemical transesterification reaction. Three process variables, namely hydrodynamic conditions, solvent to biodiesel ratio and extraction duration were investigated and their impact on the extraction efficiency was found to be largely negligible. Throughout the whole range of process variables the extraction efficiency was relatively high, getting slightly lower only during the continuous experiments. After the extraction, free glycerol content was below the limit for all samples, but the total glycerol and glycerides content was too high to fully comply with biodiesel quality standards. Selected extraction solvent has proved to be efficient for free glycerol removal in the tested range of conditions, but further process modifications and possible raw material and biodiesel processing will be needed to reduce the content of total glycerol and glycerides.
\end{abstract}

Keywords: Biodiesel, Deep Eutectic Solvents, Glycerol, Liquid-Liquid Extraction

\section{Introduction}

In the past few decades, energy demand in all economic sectors has been growing steadily. Increase in fuel consumption, most notably in the transport sector, has resulted in increased emissions of combustion products that are harmful to human health and play a significant role in global climate changes [1]. Over the past decade, great efforts have been devoted to development of alternative fuels that could replace the existing fossil ones [2]. The greatest potential has been observed in biodiesel because previous studies showed that the combustion of biodiesel reduced emissions, so biodiesel is now the most widely used renewable energy source [3]. In addition, biodiesel production will greatly relieve the transport sector i.e. its dependence on fossil fuels and it will encourage economic development, due to the availability, renewability and easy-to-use raw materials [4].

Biodiesel is synthesized by transesterification of triglycerides with homogeneous or heterogeneous catalysts, wherein the homogeneous catalysts may be alkaline or acidic, and heterogeneous catalysts may be solid catalysts or enzymes [5]. The fastest and most commonly used method for biodiesel synthesis is the alkali-catalyzed transesterification of vegetable oils, but its downside is its high dependence on the oil quality, namely the concentration of free fatty acids and water in the feedstock [6]. The reaction product is a mixture formation of alkyl (usually methyl or ethyl) esters of fatty acids, i.e. biodiesel and glycerol as by-product [7].

The increase in global demands for biodiesel production results in increasing interest for the use of waste materials of plant and animal origin or non-edible oils. The main problems associated with the use of waste materials are high proportion of free fatty acids that must be reduced to below $1 \%$ and frequent presence of water [1].

Sunflower oil is the most commonly used cooking oil in central Croatia, both in households and in student restaurants in Zagreb. Due to its high smoke point it can be used for 
baking, frying and cooking. Its acid value is normally very low even when used multiple times. Biodiesel is commercially produced mostly from the oils of rapeseed [8], soybean [9] and palm [10]. This paper is based on used sunflower oil because of its availability and potential environmental benefits of turning waste into fuel. Several papers have been published regarding sunflower oil biodiesel; Naureen at al. focused on synthesis and characterization [11], Saba et al. and Vahid et al. investigated different catalysts and influence of catalyst to fuel ratio on biodiesel conversion [12-14], Reyero at al. researched kinetics of $\mathrm{NaOH}$ catalyzed transesterification with ethanol [15] and Santala et al. did experimental and simulation studies of transesterification in microchannel reactor [16]. Encinar et al. researched the variables affecting the yields and characteristics of the biodiesel [17] and Vicente at al. compared the most common basic catalysts for methanolysis of sunflower oil [18].

Various impurities contained in synthesized biodiesel adversely affect its characteristics, its storage properties as well as engine performance and lifetime. Aside from glycerol, biodiesel often contains methanol, water, soap, catalyst, free fatty acids and unreacted tri-, di- and monoglycerides [19]. Liquid-liquid extraction is one of the alternative methods for purification of the biodiesel produced. Its advantages lie in mild conditions of the process performed at room temperature and atmospheric pressure. Some studies on vegetable oils have shown that the use of deep eutectic solvents (DESs) reduces the content of all impurities present in crude biodiesel [20-22]. Deep eutectic solvents are mixtures of two or three economically and environmentally acceptable components with a melting temperature lower than the melting temperature of individual components [23]. Their use was investigated in various processes because of their outstanding properties, the most important of which being simplicity of synthesis from environmentally friendly raw materials, non-volatility, thermal and chemical stability, non-toxicity, biodegradability and non-flammability and potential for dissolving different types of organic, inorganic and polymeric compounds [24]. Thanks to its properties, eutectic solvents are used in synthesis processes, as catalysts and biocatalysts, in electrochemical synthesis, in analytical chemistry procedures as solvents or auxiliary solvents and in separation processes. Due to their negligible environmental impact as well as simple and inexpensive synthesis, DESs are interesting both on laboratory and industrial scale [25].

Using deep eutectic solvents for glycerol removal is a fairly new method and only several papers have been published investigating different DESs, biodiesel to DES ratios and temperatures during extraction. Among the DESs used, choline chloride seems to be the most common salt and ethylene glycol and glycerol are the most common hydrogen bond donors. Shahbaz et al. used choline chloride with ethylene glycol and with 2,2,2-trifluracetamide in different molar ratios [20] while Ho et al. used ternary deep eutectic solvents - choline chloride with both ethylene glycol and glycerol in different molar ratios [26]. Both papers report free glycerol removal and substantial total glycerol reduction for almost all experiments conducted.

In this article, the applicability of deep eutectic solvent, choline-chloride: ethylene-glycol (molar ratio 1: 2.5) for extraction of glycerol from biodiesel was tested experimentally in batch and continuous extractor. That particular DES was chosen because, unlike a lot of other DESs, its viscosity is relatively low what results in lower flow resistance effectively aiding the mixing process and reducing the power needed to pump the solvent during continuous setup. It is fairly cheap, even when p.a. quality. Having in mind a future scale-up to an industrial scale, it is important that all resistances in the system and the price of components are minimised. Also, it is crucial that the solvent is stable in the entire expected temperature range (expected temperature in an open industrial environment, ranging from 0 to $60^{\circ} \mathrm{C}$ ). During preliminary experiments for this work, DES choline-chloride: ethylene-glycol (molar ratio 1:2) was noticed to begin to crystallize at around $15^{\circ} \mathrm{C}$ so it was not used in extraction experiments. Lastly, Shahbaz et al. reported that among the choline-chloride: ethylene-glycol DESs they used for glycerol extraction, the solvent with molar ratio 1:2.5 appeared to be the most efficient one [20], so in this paper its utilisation was tested in both batch and continuous setup in an effort to determine the optimal process conditions for a possible future industrial use.

\section{Materials and Methods}

\subsection{Preparation of Deep Eutectic Solvent}

Choline chloride and ethylene glycol were dried in the vacuum dryer at $60^{\circ} \mathrm{C}$ for 8 hours before use. Cholinium salt and hydrogen bond donor (molar ratio 1:2.5) were directly weighed in a flask and the mixture was placed on a rotary vacuum evaporator $\left(250 \mathrm{mbar}\right.$ and $\left.60^{\circ} \mathrm{C}\right)$ until clear liquid is obtained.

\subsection{Biodiesel Synthesis}

Biodiesel was synthesized by alkali-catalyzed $(\mathrm{NaOH})$ transesterification of fresh and waste cooking sunflower oil of satisfactory quality with methanol. $0.6 \mathrm{~g}$ of $\mathrm{NaOH}$ was dissolved in $20 \mathrm{~mL}$ of methanol. Sodium methoxide was added to the filtrated oil heated at $55^{\circ} \mathrm{C}$ and intensively mixed. Heterogeneous mixture was left for 24 hours to ensure complete phase separation. Three different types of waste sunflower oil were used for the synthesis of biodiesel (french fries, potato with paprika and doughnut).

\subsection{Extraction of Free Glycerol}

Liquid-liquid extraction experiments were carried out in a laboratory batch extractor (internal diameter of $0.04 \mathrm{~m}$ ) equipped with a magnetic stirrer and Karr column (column height: $0.43 \mathrm{~m}$; column diameter: $0.05 \mathrm{~m}$; perforated plate diameter: plate free flow area: $22 \% ; 0.043 \mathrm{~m}$; number of plates: 11; distance between plates: $0.04 \mathrm{~m}$ ). Karr column 
was equipped with two phase separators and two peristaltic pumps. For the batch extraction, the influence of extraction duration $(15-60 \mathrm{~min})$, hydrodynamic conditions $(150,300$, $500,700 \mathrm{rpm})$ and the mass ratio (solvent: crude biodiesel) $\left(0.25,0.50,0.75,1.00 \mathrm{~kg} \mathrm{~kg}^{-1}\right)$ on the extraction efficiency and the quality of the purified biodiesel was investigated. Continuous extraction was performed at different pulsation rate $(27,34,54,63$ pulsation per minute) and extraction duration $(5-20 \mathrm{~min})$.

\subsection{Characterization of Deep Eutectic Solvent, Oil and Biodiesel}

Analytical methods used for biodiesel characterization are: FTIR (Bruker Vertex 70), GC Shimadzu GC-2014) and ${ }^{1} \mathrm{H}$ NMR (Bruker Avance 300). Viscosity was measured on a Brookfield DV-III Ultra Programmable Rheometer. Density was measured with a Mettler Toledo densitometer Densito 30PX. Biodiesel heating value (LHV) was measured with calorimeter IKA C 2000. Acid number of waste cooking oil was determined according to the standard method HRN EN ISO 660:2010 and iodide number according to the standard method HRN EN ISO 3961:2013.

\section{Results and Discussion}

This study covers preparation of choline-chloride: ethyleneglycol (molar ratio 1:2.5), synthesis of biodiesel from fresh and waste cooking sunflower oil and its purification as well as characterization of the obtained products. Synthesized biodiesels were purified by means of liquid-liquid extraction with choline-chloride: ethylene-glycol (molar ratio 1: 2.5) in different process conditions. For the best of our knowledge the influence of the process conditions (hydrodynamic conditions, mass ratio solvent/biodiesel and time of extraction) wasn't investigated previously.

The applicability of the selected DES for the extraction of glycerol from biodiesel is evaluated in terms of extraction efficiency, which is calculated from the mass fraction of glycerol before and after extraction, obtained by GC analysis:

$$
\varepsilon=\frac{w_{g}^{F}-w_{g}^{R}}{w_{g}^{F}} \cdot 100 \%
$$

Standard uncertainties were calculated by the following equation:

$$
u\left(w_{i}\right)=\left(\frac{1}{n \cdot(n-1)} \cdot \sum_{k=1}^{n}\left(w_{i, k}-\bar{w}_{i}\right)^{2}\right)^{1 / 2}
$$

\subsection{Batch Extraction}

\subsubsection{The Influence of the Quality of Raw Material on the Extraction Efficiency}

In order to investigate the influence of the type of raw material used for biodiesel (fresh and waste sunflower oil) on the extraction of free and total glycerol from biodiesel, one set of batch experiments (mass ratio DES: biodiesel: $0.25 \mathrm{~kg}$ $\mathrm{kg}^{-1}$ at $500 \mathrm{rpm}$ for 30 minutes) was conducted. Concentrations of free and total glycerol in crude biodiesels as well as in purified biodiesels were measured three times. Standard uncertainties were lower than 0.006 . Based on the obtained results (Figure 1) it can be concluded that the extraction efficiency is influenced by the concentration of free and total glycerol. Higher concentrations of free and total glycerol resulted with higher efficiency. Since the extraction time was the same for all experiments, higher concentration means larger driving force for mass transfer and consequently lower final concentration of free and total glycerol in biodiesel. After extraction, all biodiesel samples had the final concentration of free and total glycerol higher than the maximum allowed, probably due to the low DES: biodiesel mass ratio. Biodiesel synthesised from fresh sunflower oil had the lowest concentration of free and total glycerol before extraction, and the highest concentrations after extraction. All other experiments were carried out with biodiesel with the highest concentration of glycerol.

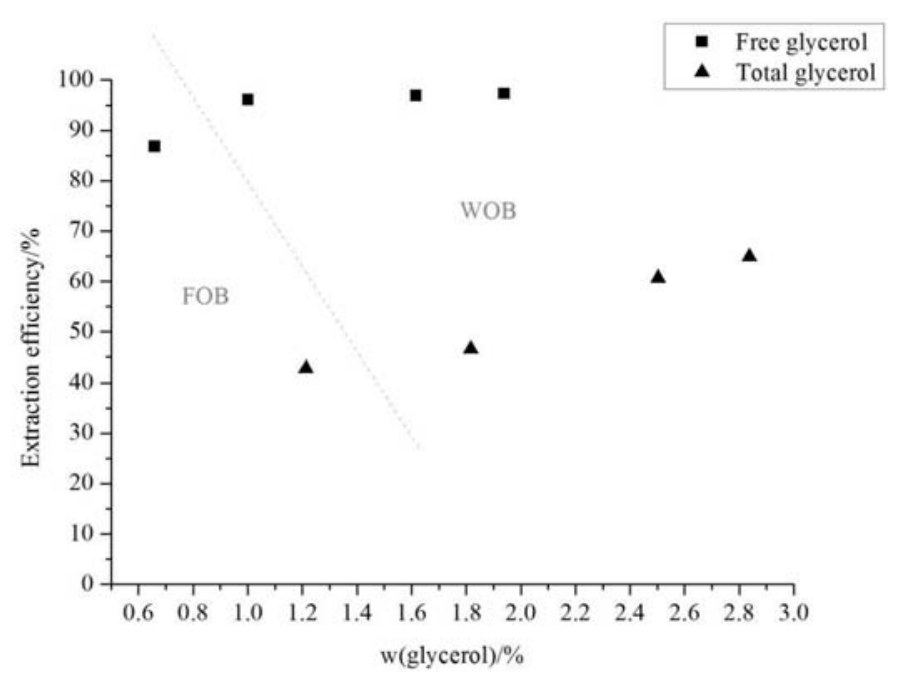

Figure 1. Influence of the type of biodiesel on the extraction efficiency (DES: biodiesel mass ratio $=0.25 ; t=30$ min; $n=500 \mathrm{rpm}$ ). 


\subsubsection{The Influence of the Process Conditions on the Extraction Efficiency}

Table 1 shows influence of the hydrodynamic conditions, mass ratio DES: biodiesel and extraction duration for batch extraction on the extraction efficiency. The initial concentration of free and total glycerol in biodiesel was 1.939 and $2.836 \%$ respectively. Increase of the mixing intensity, mass ratio DES: biodiesel and extraction duration do not significantly influence the extraction efficiency. High extraction efficiencies for free glycerol were obtained at all process conditions investigated for the batch extraction. Since the concentration of total glycerol was also decreased for more than $64 \%$, selected solvent was efficient for extraction of mono-, di- and triglycerides.

Table 1. The influence of the process conditions on the extraction efficiency.

\begin{tabular}{|c|c|c|c|}
\hline \multirow{2}{*}{\multicolumn{2}{|c|}{ Process conditions }} & \multicolumn{2}{|c|}{ Extraction efficiency/\% } \\
\hline & & Free glycerol & Total glycerol \\
\hline \multirow{5}{*}{$\begin{array}{l}\text { Hydrodynamic } \\
\text { conditions/ rpm }\end{array}$} & & Batch extraction & \\
\hline & 150 & 98.40 & 70.53 \\
\hline & 300 & 98.45 & 67.86 \\
\hline & 500 & 97.32 & 64.95 \\
\hline & 700 & 98.40 & 70.76 \\
\hline \multirow{4}{*}{$\begin{array}{l}\text { Mass ratio DES: } \\
\text { biodiesel } / \mathrm{kg} \mathrm{kg}^{-1}\end{array}$} & 0.25 & 97.32 & 64.95 \\
\hline & 0.50 & 99.07 & 70.46 \\
\hline & 0.75 & 96.36 & 67.05 \\
\hline & 1.00 & 98.40 & 71.86 \\
\hline \multirow{4}{*}{$\begin{array}{l}\text { Extraction } \\
\text { duration/min }\end{array}$} & 15 & 96.91 & 68.25 \\
\hline & 30 & 97.32 & 64.95 \\
\hline & 45 & 97.83 & 65.47 \\
\hline & 60 & 97.11 & 66.81 \\
\hline
\end{tabular}

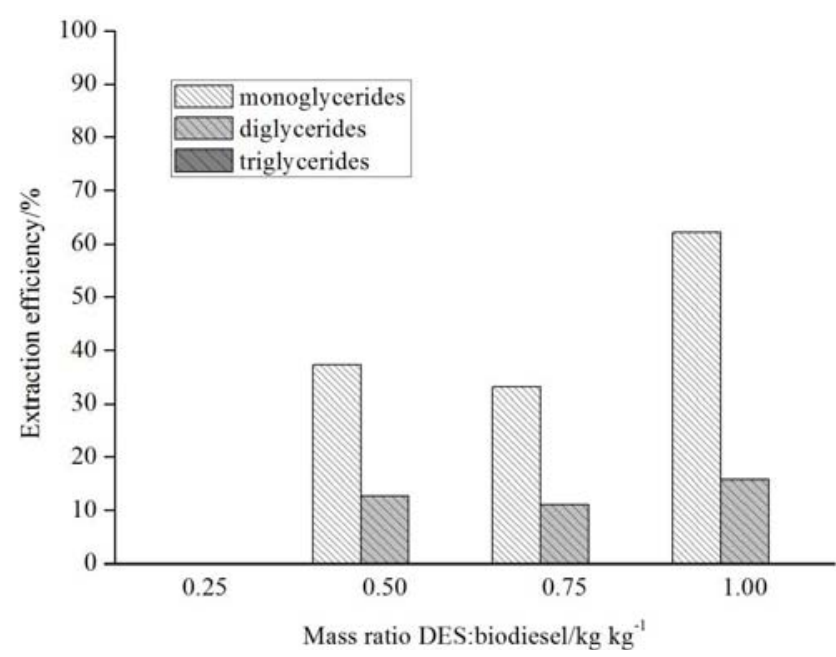

Figure 2. The influence of the DES: biodesel mass ratio on the extraction efficiency $(t=30 \mathrm{~min} ; n=500 \mathrm{rpm})$.

The ability of the selected solvent to extract mono-, di- and triglycerides is clearly visible in Figures 2 and 3. For the DES: biodiesel mass ratios lower than $0.5 \mathrm{~kg} \mathrm{~kg}^{-1}$, glycerides were not transferred from biodiesel to DES. As the quantity of DES was increased, higher extraction efficiencies could be observed, for mono- and diglycerides. Based on the presented results, triglycerides were not transferred to the DES. When stationary state was achieved in the continuous process, the maximum quantity of mono-, di- and triglycerides was transferred from biodiesel to DES. Higher amount of the extracted di- and triglycerides can be attributed to the higher DES: biodiesel mass ratio $(5: 1)$ than used for batch experiments (up to 1: 1). It is obvious that the solubility is increased from triglycerides to monoglycerides. It is also possible that the rate of mass transfer from biodiesel to DES is the highest for monoglycerides which are smaller molecules of simpler structure than di- or triglycerides. In batch extraction experiments, the capacity of solvent for diand triglycerides is reduced due to the increased concentration of monoglycerides in DES.

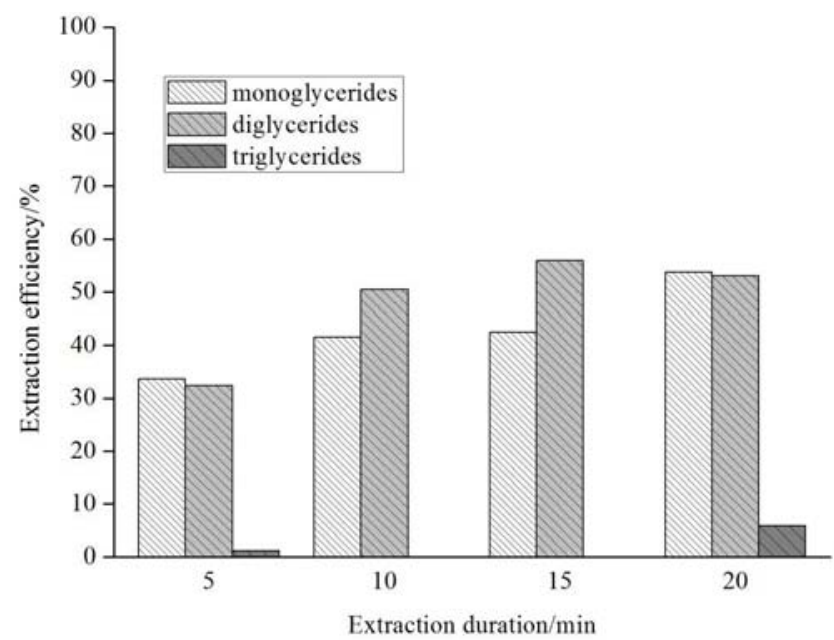

Figure 3. The influence of the extraction time on the extraction efficiency $\left(D E S\right.$ : biodiesel mass ratio $=5: 1 ;$ pulsation rate $=54$ pul $\left.\mathrm{min}^{-1}\right)$.

\subsection{Continuous Column Extraction}

In order to investigate the influence of oil type on the composition and properties of biodiesel, biodiesel was synthesised from fresh sunflower oil and purified by the same solvent in the column extractor. The influence of the extraction duration on the extraction efficiency is shown in table 2. Higher extraction efficiency for glycerides was obtained for continuous extraction experiments. Low value after 5 minutes means that stable state wasn't achieved. Higher extraction efficiency is achieved since higher DES: biodiesel mass ratio (5: 1) was used.

Table 2. The influence of extraction duration on the extraction efficiency.

\begin{tabular}{|c|c|c|c|}
\hline \multirow{3}{*}{\multicolumn{2}{|c|}{ Process conditions }} & \multicolumn{2}{|c|}{ Extraction efficiency/\% } \\
\hline & & Free glycerol & Total glycerol \\
\hline & & \multicolumn{2}{|c|}{ Continuous extraction } \\
\hline \multirow{4}{*}{$\begin{array}{l}\text { Extraction } \\
\text { duration/min }\end{array}$} & 5 & 17.86 & 17.25 \\
\hline & 10 & 96.39 & 80.52 \\
\hline & 15 & 96.29 & 81.52 \\
\hline & 20 & 97.78 & 82.26 \\
\hline
\end{tabular}

The extraction performance of the continuous countercurrent column extraction was also studied at different mixing intensities. Time needed for stabilization was 20 minutes. The FTIR spectra for purified biodiesels obtained at different pulsation rates are presented in Figure 4. 
In the region from $1800-1700 \mathrm{~cm}^{-1}$, peak that can be attributed to the stretching of $\mathrm{C}=\mathrm{O}$, typical of esters, and thus common in FAME spectra, can be observed. The influence of the pulsation rate on the removal of glycerol from biodiesel can also be observed in Figure 4. The intensity of broad strong band between 3200 and $3600 \mathrm{~cm}^{-1}$ that corresponds to alcohols is decreased with increasing pulsation rate. This is clearly visible from the influence of the pulsation rate on the area below this peak.

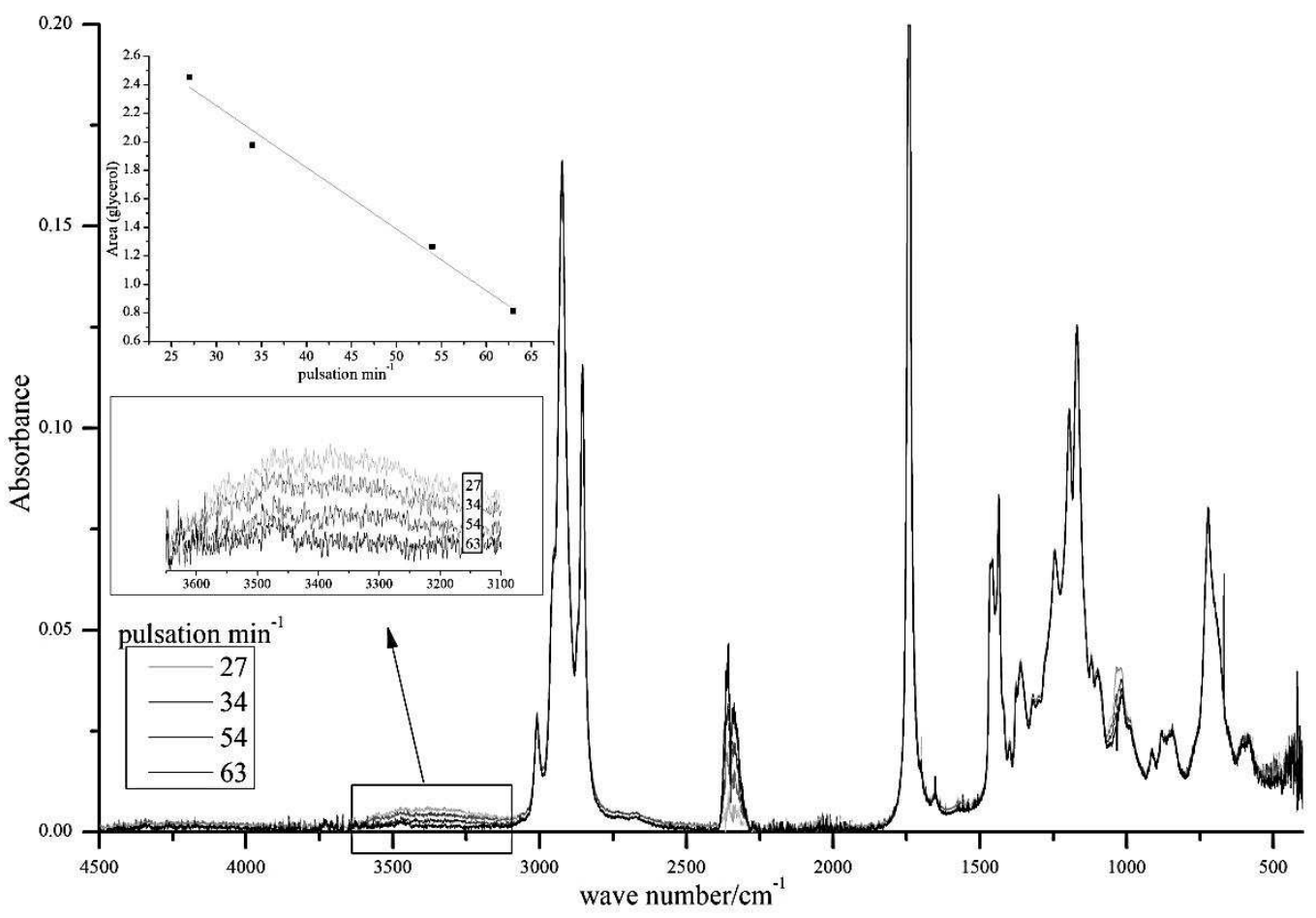

Figure 4. FTIR spectra of waste cooking oil biodiesel at different pulsation rates (DES: biodiesel mass ratio $=5: 1)$.

Table 3 shows the most important physical properties of purified biodiesel produced from fresh and waste cooking sunflower oil (DES: biodiesel mass ratio $=5: 1 ; 20$ minutes; $54 \mathrm{pul} / \mathrm{min}$ ) as well as density and viscosity of DES. Experimentally determined acid number of both oils is low enough to ensure high efficiency of the transesterification process. Viscosity and density of biodiesels meets the EN 14214 specification standard. Heating values are lower than the heating value of fossil diesel $\left(42.6 \mathrm{~kJ} \mathrm{~g}^{-1}\right)$ as stated in the literature [27].

Table 3. Properties of deep eutectic solvent, fresh (FSO) and waste sunflower oil (WSO) and biodiesel (from fresh oil: FSB; from waste oil: $W S B)$.

\begin{tabular}{lllll}
\hline & $\rho / \mathbf{k ~ c m}^{-3}$ & $\eta /$ Pa s & $\mathbf{m g}(\mathbf{K O H}) / \mathbf{g}(\mathbf{o i l})$ & $\mathbf{L H V} / \mathbf{J ~ g}^{-1}$ \\
\hline DES & 1.122 & 0.0355 & - & - \\
FSO & 0.919 & 0.0584 & 0.560 & - \\
FSB & 0.880 & 0.0388 & - & - \\
WSO & 0.920 & 0.0509 & 0.688 & 39880.0 \\
WSB & 0.887 & 0.0043 & - & 39876.5 \\
\hline
\end{tabular}

The chemical structure of biodiesel in terms of carbon chains, saturated and unsaturated fatty acid methyl esters and mass percentage are given in Table 4, as determined by GC analysis. According to Table 4, both biodiesels are composed mainly from unsaturated fatty acid methyl esters and their composition is similar.
Table 4. Fatty acid methyl ester concentration in biodiesel (WO - waste oil; FO-fresh oil).

\begin{tabular}{|c|c|c|c|}
\hline \multirow{2}{*}{ FAME } & \multirow{2}{*}{ structure } & \multicolumn{2}{|l|}{$\mathrm{w} / \%$} \\
\hline & & WO & FO \\
\hline Caproic acid methyl ester & C6:0 & 0.0147 & 0.0156 \\
\hline Caprylic acid methyl ester & $\mathrm{C} 8: 0$ & 0.0274 & 0.0078 \\
\hline Capric acid methyl ester & $\mathrm{C} 10: 0$ & 0.0242 & 0.0357 \\
\hline Undecylic acid methyl ester & $\mathrm{C} 11: 0$ & 0.0074 & 0.0335 \\
\hline Lauric acid methyl ester & $\mathrm{C} 12: 0$ & 0.0158 & 0.0123 \\
\hline Tridecylic acid methyl ester & $\mathrm{C} 13: 0$ & 0.0021 & - \\
\hline Mystric acid methyl ester & $\mathrm{C} 14: 0$ & 0.0905 & 0.0769 \\
\hline Tetradeceonic acid methyl ester & $\mathrm{C} 14: 1$ & 0.0084 & 0.0112 \\
\hline Pentadecylic acid methyl ester & $\mathrm{C} 15: 0$ & 0.0399 & 0.0379 \\
\hline Palmitic acid methyl ester & $\mathrm{C} 16: 0$ & 6.3641 & 5.9454 \\
\hline Palmitoleic acid methyl ester & C16:1 & 0.1284 & 0.1238 \\
\hline Margaric acid methy ester & $\mathrm{C} 17: 0$ & 0.0589 & 0.0602 \\
\hline Stearic acid methyl ester & $\mathrm{C} 18: 0$ & 2.8827 & 2.8367 \\
\hline Oleic acid methyl ester & C18:1 & 27.6185 & 26.4902 \\
\hline Linoleic acid methyl ester & C18:2 & 55.3307 & 55.6710 \\
\hline Linolenic acid methyl ester & $\mathrm{C} 18: 3$ & 0.2914 & 0.1918 \\
\hline Arachidic acid methyl ester & $\mathrm{C} 20: 0$ & 0.2619 & 0.2509 \\
\hline Paulinic acid methyl ester & $\mathrm{C} 20: 1$ & 0.1852 & 0.1717 \\
\hline Eicosapentaenoic acid methyl ester & $\mathrm{C} 20: 5$ & 0.0174 & 0.0268 \\
\hline Behenic acid methyl ester & $\mathrm{C} 22: 0$ & 0.6197 & 0.6021 \\
\hline Erucic acid methyl ester & $\mathrm{C} 22: 1$ & 0.0263 & 0.0223 \\
\hline Lignoceric acid methyl ester & $\mathrm{C} 24: 0$ & 0.2146 & 0.2052 \\
\hline Nervonic acid methyl ester & $\mathrm{C} 24: 1$ & 0.0253 & 0.0234 \\
\hline Saturated & & 10.6239 & 10.1202 \\
\hline Monousaturated & & 27.9921 & 26.8426 \\
\hline Polyunsaturated & & 55.6395 & 55.8896 \\
\hline
\end{tabular}


${ }^{1} \mathrm{H}$ NMR spectrums of biodiesel before and after extraction are presented in Figure 5. The characteristic intense peak of methoxy protons is observed at $3.624 \mathrm{ppm}$ and $\alpha-\mathrm{CH} 2$ protons signal at $2.279 \mathrm{ppm}$. These two peaks are the distinct peaks for confirmation of methyl esters present in the biodiesel. Other peaks were at $0.876-0.927 \mathrm{ppm}$ of terminal methyl protons, a strong signal at $1.182-1.461 \mathrm{ppm}$ related to methylene protons and 5.206-5.433 ppm assigned to olefinic hydrogens. ${ }^{1} \mathrm{H}$ NMR can also be used to quantify the conversion of vegetable oil in methyl esters by transesterification reaction [28]. The relevant signals chosen for integration were those of the methoxy group in the methyl esters at $3.624 \mathrm{ppm}(\mathrm{AMe})$ and of the $\alpha$-carbonyl methylene protons at $2.279 \mathrm{ppm}(\mathrm{ACH} 2)$. The equation used to quantify the yield of transesterification was:

$$
\% F A M E=100 \cdot \frac{2 \cdot A \mathrm{Me}}{3 \cdot A \mathrm{CH} 2}
$$

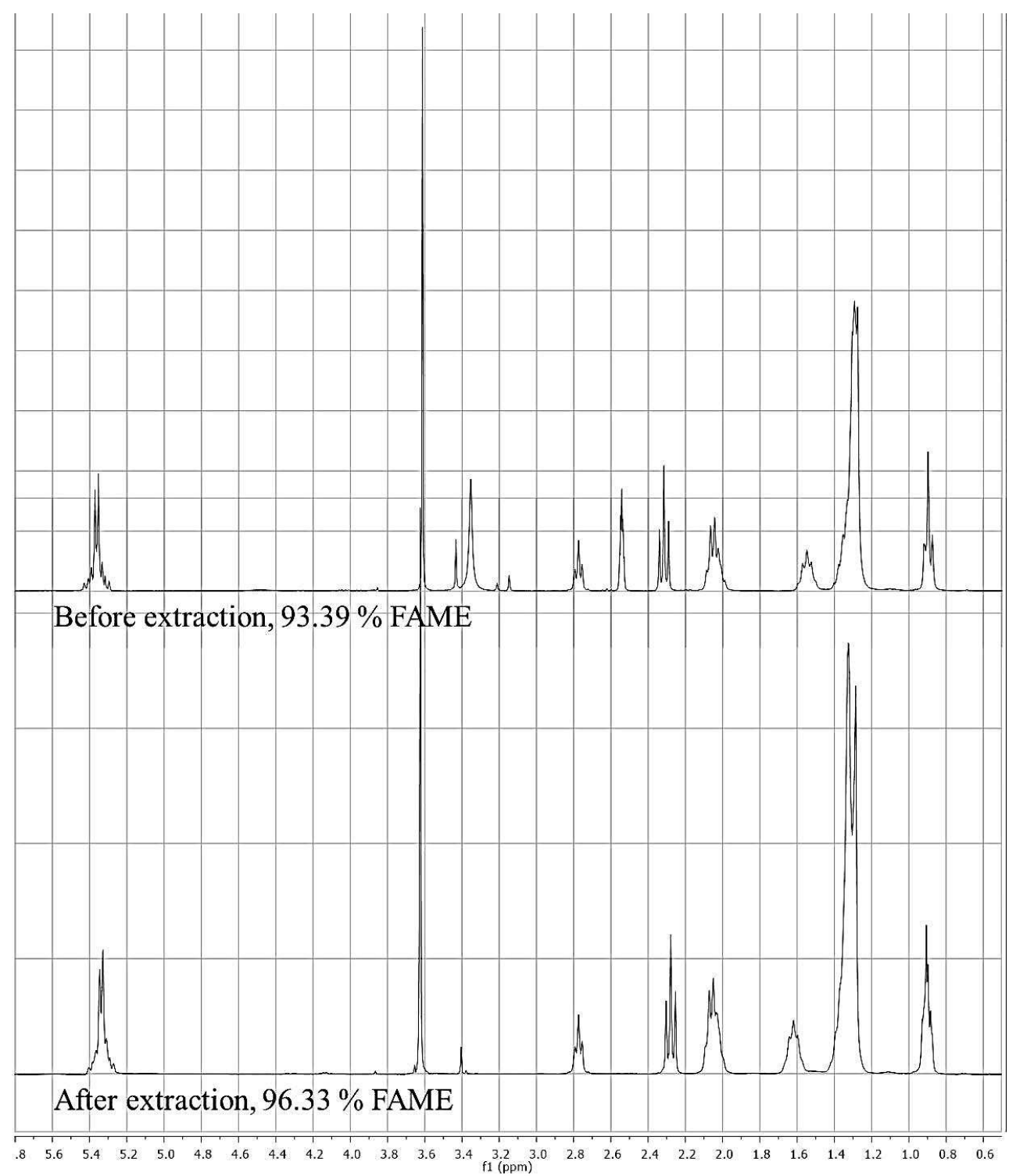

Figure 5. ${ }^{1} H$ NMR spectra of biodiesel $(W O B)$ before and after extraction.

Percentage conversion of triglycerides to the corresponding methyl esters after extraction is slightly higher than the one before extraction, probably due to the higher purity of biodiesel. Peaks characteristic for alcohols, from 3.4 to $4.0 \mathrm{ppm}$ are significantly lower after extraction which means that both methanol and glycerol were extracted from biodiesel.

Table 5 shows the biodiesel specifications according to the EN 14214 standard. After purification, the biodiesel fulfilled the standard specifications for biodiesel fuel in terms of free glycerine content. However, the ester content was slightly lower than the EN 14214 limit due to the higher concentrations of mono-, di- and triglycerides. Iodide number is higher than the standard value $\left(120 \mathrm{~g}\left(\mathrm{I}_{2}\right) / \mathrm{g}\right.$ (oil)) due to the higher concentration of unsaturated FAME. Biodiesel of slightly higher quality was produced from waste sunflower oil since the concentration of mono-, di- and triglycerides was reduced, probably during frying. 
Table 5. Specification of biodiesel after continuous extraction

\begin{tabular}{|c|c|c|c|c|c|}
\hline property & unity & FOB & WOB & standard & method \\
\hline Ester content & $\%(\mathrm{~m} / \mathrm{m})$ & 94.6 & 96.1 & $>96.5$ & HRN EN ISO 23015:1997 \\
\hline Sulfated ash content & $\%(\mathrm{~m} / \mathrm{m})$ & 0.011 & 0.012 & $<0.02$ & HRN EN ISO 3987:2011 \\
\hline Sulfur content & $\mathrm{mg} / \mathrm{kg}$ & $<3$ & $<3$ & $<10$ & HRN EN ISO 20846:2011 \\
\hline Methanol content & $\%(\mathrm{~m} / \mathrm{m})$ & $<0.1$ & $<0.1$ & $<0.2$ & HRN DIN EN 14110:2003 \\
\hline Iodide number & $\mathrm{g} \mathrm{I}_{2} / 100 \mathrm{~g}$ & 126.2 & 125 & $<120$ & HRN EN 16300:2012 \\
\hline Linolenic acid methyl ester & $\%(\mathrm{~m} / \mathrm{m})$ & 0.2 & 0.3 & $<12$ & HRN EN 14103:2011 \\
\hline Monoglyceride content & $\%(\mathrm{~m} / \mathrm{m})$ & 0.67 & 0.56 & $<0.7$ & HRN EN 14105:2011 \\
\hline Diglyceride content & $\%(\mathrm{~m} / \mathrm{m})$ & 1.27 & 0.91 & $<0.2$ & HRN EN 14105:2011 \\
\hline Triglyceride content & $\%(\mathrm{~m} / \mathrm{m})$ & 3.11 & 2.36 & $<0.2$ & HRN EN 14105:2011 \\
\hline Free glycerine & $\%(\mathrm{~m} / \mathrm{m})$ & $<0.005$ & $<0.005$ & $<0.02$ & HRN EN 14105:2011 \\
\hline Total glycerine & $\%(\mathrm{~m} / \mathrm{m})$ & 0.677 & 0.521 & $<0.25$ & HRN EN 14105:2011 \\
\hline
\end{tabular}

\section{Conclusions}

In this study, deep eutectic solvent choline-chloride: ethylene-glycol (molar ratio 1:2.5) was employed as solvent for the removal of glycerol from biodiesel produced from waste cooking sunflower oil. For this purpose, the effectiveness of using the selected DES on the removal of free glycerol, bound glycerol, and total glycerol was investigated in different process conditions. Based on the obtained results, there was no significant effect of hydrodynamic conditions and mass ratio DES: biodiesel on the extraction efficiency, due to the high solvation capacity of selected deep eutectic solvent. Time needed to reach the stable state in the column extractor was 20 minutes. Cholinechloride: ethylene-glycol (molar ratio 1:2.5) was found to be successful to reduce the free glycerol and methanol from biodiesel below the standard value as well as to reduce the content of mono-di and triglycerides. By selecting the proper mass ratio DES: biodiesel, choline-chloride: ethylene-glycol (molar ratio 1:2.5) can be used for purification of crude biodiesel due to its ability to remove the major impurities from biodiesel.

\section{List of Symbols and Abbreviations}

\section{Symbols}

$\varepsilon-$ extraction efficiency $/ \%$

$n-$ mixing intensity/rpm

$t$ - time/min

$u\left(w_{\mathrm{i}}\right)-$ standard uncertainity

$w_{g}^{F}$ - weight fraction of glycerol in feed

$w_{g}^{R}$ - weight fraction of glycerol in raffinate

\section{Abbreviations}

${ }^{1} \mathrm{H}$ NMR - proton nuclear magnetic resonance

DES - deep eutectic solvent

FAME - fatty acid methyl esters

$\mathrm{FO}$ - fresh oil

FOB - fresh oil biodiesel
FTIR - Fourier transformation infrared spectroscopy

GC - gas chromatography

$\mathrm{LHV}$ - lower heating value $/ \mathrm{J} \mathrm{g}^{-1}$

WO - waste oil

WOB - waste oil biodiesel

\section{References}

[1] Banković-Ilić I. B., Stojković I. J., Stamenković O. S., Veljković $V$. B., Hung, Y.-T., Waste animal fats as feedstocks for biodiesel production, Renew. Sust. Energ. Rev. 32 (2014) 238.

[2] Guru M., Koca A., Can O., Çınar C., Sahin F., Biodiesel production from waste chicken fat based sources and evaluation with $\mathrm{Mg}$ based additive in a diesel engine, Renew. Energ. 35 (2010) 637.

[3] Dufour J., Iribarren D., Life cycle assessment of biodiesel production from free fatty acid-rich wastes, Renew. Energ. 38 (2012) 155.

[4] Chakraborty R., Gupta A. K., Chowdhury R., Conversion of slaughterhouse and poultry farm animal fats and wastes to biodiesel: Parametric sensitivity and fuel quality assessment, Renew. Sust. Energ. Rev. 29 (2014) 120.

[5] Atadashi I. M., Aroua M. K., Abdul Aziz A. R., Sulaiman N. M. $N$., The effects of catalysts in biodiesel production: A review, J. Ind. Eng. Chem. 19 (2013) 14.

[6] Soltani S., Rashid U., Yunus R., Taufiq-Yap Y. H., Synthesis of Biodiesel through Catalytic Transesterification of Various Feedstocks using Fast Solvothermal Technology: A Critical Review, Catal. Rev. 57 (2015) 407.

[7] Santacesaria E., Martinez Vicente G., Di Serio M., Tesser R., Main technologies in biodiesel production: State of the art and future challenges, Catal. Today 195 (2012) 2.

[8] Komers, K., Stloukal, R., Machek, J., Skopal, F., Biodiesel from rapeseed oil, methanol and $\mathrm{KOH}$. 3. Analysis of composition of actual reaction mixture, Eur. J. Lipid Sci. Tech. 103 (2001) 363.

[9] Candeia, R. A., Silva, M. C. D., Carvalho Filho, J. R., Brasilino, M. G. A., Bicudo, T. C., Santos, I. M. G., Souza, A. $G$., Influence of soybean biodiesel content on basic properties of biodiesel-diesel blends, Fuel 88 (2009) 738. 
[10] Benjumea, P., Agudelo, J., Agudelo, A., Basic properties of palm oil biodiesel-diesel blends, Fuel 87 (2008) 2069.

[11] Naureen, R., Tariq, M., Yusoff, I., Chowdhury, A. J. K., Ashraf, M. A., Synthesis, spectroscopic and chromatographic studies of sunflower oil biodiesel using optimized base catalyzed methanolysis, Saudi J. Biol. Sci. 22 (2015) 332.

[12] Saba, T., Estephane, J., El Khoury, B., El Khoury, M., Khazma, M., El Zakhem, H., Aouad, S., Biodiesel production from refined sunflower vegetable oil over $\mathrm{KOH} / \mathrm{ZSM} 5$ catalysts, Renew. Energ. 90 (2016) 301.

[13] Vahid, B. R., Haghighi, M., Biodiesel production from sunflower oil over $\mathrm{MgO} / \mathrm{MgAl}_{2} \mathrm{O}_{4}$ nanocatalyst: Effect of fuel type on catalyst nanostructure and performance, Energ. Convers. Manage. 134 (2017) 290.

[14] Vahid, B. R., Haghighi, M., Urea-nitrate combustion synthesis of $\mathrm{MgO} / \mathrm{MgAl}_{2} \mathrm{O}_{4}$ nanocatalyst used in biodiesel production from sunflower oil: Influence of fuel ratio on catalytic properties and performance, Energ. Convers. Manage. 126 (2016) 362 .

[15] Reyero, I., Arzamendi, G., Zabala, S., Gandia, L. M., Kinetics of the $\mathrm{NaOH}$-catalyzed transesterification of sunflower oil with ethanol to produce biodiesel, Fuel Process. Technol. 129 (2015) 147.

[16] Santana, H. S., Tortola, D. S., Reis, E. M., Silva, J. L. Taranto, $O$. P., Transesterification reaction of sunflower oil and ethanol for biodiesel synthesis in microchannel reactor: Experimental and simulation studies, Chem. Eng. J. 302 (2016) 752.

[17] Encinar, J. M., Gonzalez, J. F., Rodríguez-Reinares, A., Biodiesel from used frying oil. Variables affecting the yields and characteristics of the biodiesel, Ind. Eng. Chem. Res. 44 (2005) 5491.

[18] Vicente, G., Martınez, M., Aracil, J., Integrated biodiesel production: a comparison of different homogeneous catalysts systems, Bioresource Technol. 92 (2004) 297.

[19] Stojković I. J., Stamenković O. S., Povrenović D. S., Veljković $V$. B., Purification technologies for crude biodiesel obtained by alkali-catalyzed transesterification, Renew. Sust. Energ. Rev. 32 (2014) 1 .

[20] Shahbaz K., Mjalli F. S., Hashim M. A., Al-Nashef I. M., Using Deep Eutectic Solvents for the Removal of Glycerol from Palm Oil- Based Biodiesel, J. Appl. Sci. 10 (2010) 3349.

[21] Huang $W$., Tang S., Zhao H., Tian S., Activation of Commercial $\mathrm{CaO}$ for Biodiesel Production from Rapeseed Oil Using a Novel Deep Eutectic Solvent, Ind. Eng. Chem. Res. 52 (2013) 11943.

[22] Tang B., Zhang H., Row K. H., Application of deep eutectic solvents in the extraction and separation of target compounds from various samples, J. Sep. Sci. 38 (2015) 1053.

[23] Abbott A. P., Harris R. C., Ryder K. S., D'Agostino C., Gladden L. F., Mantle M. D., Glycerol eutectics as sustainable solvent systems, Green Chem. 13 (2011) 82.

[24] Verevkin S. P., Sazonova A. Y., Frolkova A. K., Zaitsau D. H., Prikhodko I. V., Held C., Separation Performance of Bio Renewable Deep Eutectic Solvents, Ind. Eng. Chem. Res. 54 (2015) 3498.

[25] Tang S., Baker G. A., Zhao H., Ether- and alcoholfunctionalized task-specific ionic liquids: attractive properties and applications, Chem. Soc. Rev. 41 (2012) 4030.

[26] Ho, K. C., Shahbaz, K., Rashmi, W., Mjalli, F. S., Hashim, M. A., Al-Nashef, I. M.,_Removal of glycerol from palm oil-based biodiesel using new ionic liquids analogues, J. Eng. Sci. Technol, 10 (2015) 98.

[27] Guru M., Dogan Artukog B., Keskin A., Koca A., Biodiesel production from waste animal fat and improvement of its characteristics by synthesized nickel and magnesium additive, Energ. Convers. Manage. 50 (2009) 498.

[28] Samios D., Pedrotti F., Nicolau A., Reiznautt Q. B., Martini D. D., Dalcin F. M., A Transesterification Double Step Process - TDSP for biodiesel preparation from fatty acids triglycerides, Fuel Process. Technol. 90 (2009) 599. 